\title{
Pendidikan Ibu dan Durasi Pemberian Air Susu Ibu dalam Peningkatan Kecerdasan Siswa Usia Sekolah Dasar
}

\author{
Mother Education and Breastfeeding Duration in Increasing Elementary \\ School Students Intelligence
}

\author{
Maryam Said* Hadi Pratomo**
}

\begin{abstract}
*Dinas Kesehatan Kota Bekasi, **Departemen Pendidikan Kesehatan dan Ilmu Perilaku Fakultas Kesehatan Masyarakat Universitas Indonesia
\end{abstract}

\begin{abstract}
Abstrak
Riwayat pemberian Air Susu Ibu (ASI), karakteristik ibu dan anak serta pola asuh berpengaruh terhadap kecerdasan anak. Penelitian ini bertujuan untuk mengetahui proporsi tingkat kecerdasan anak, riwayat pemberian ASI, karakteristik ibu dan anak, serta faktor dominan yang berhubungan dengan tingkat kecerdasan anak pada siswa SDSN Pekayon Jaya VI Kota Bekasi. Penelitian kuantitatif dengan desain potong lintang dengan metode systematic random sampling dengan jumlah sampel sebesar 166 responden (siswa/i yang berumur $7-9$ tahun) beserta ibunya. Penelitian ini dilaksanakan pada bulan Mei 2013. Pada siswa dilakukan tes kecerdasan menggunakan tes Raven sedangkan ibunya mengisi kuesioner. Hasil penelitian menunjukkan tingkat kecerdasan rendah $6 \%$, rata-rata $36,7 \%$, dan tinggi $57,2 \%$. Variabel yang berhubungan dengan kecerdasan adalah durasi pemberian ASI dan pendidikan ibu. Pendidikan ibu adalah faktor dominan terhadap kecerdasan, bahwa ibu yang berpendidikan tinggi berpeluang mempunyai anak dengan kecerdasan tinggi yaitu 3,556 kali lebih besar dibandingkan ibu berpendidikan rendah setelah dikontrol variabel durasi ASI. Untuk Dinas Pendidikan Kota Bekasi agar menyelenggarakan berbagai aktivitas seperti seminar/pelatihan/konseling bagi orang tua murid tentang pentingnya peran orangtua terhadap tumbuh kembang anak.
\end{abstract}

Kata kunci: Durasi pemberian ASI, kecerdasan, pendidikan ibu

\section{Abstract}

Breastfeeding history, mother and children characteristics, and child care are considered influential on child intellegence. This study aimed to determine the proportion of exclusive breastfeeding, the level of childrens intellegence, mother and children characteristics, the relationship between duration of breastfeeding with the level of students intellegence. This research used a cross-sectional design and through systematic random sampling with a sample size of 166 respondents (students aged $7-9$ years old) and their mothers. The intellegence was tested using the Raven test while their mothers were interviewed. The results showed that the level of childrens intellegence was high $(57.2 \%)$, average $(36.7 \%)$, and low $(6 \%)$. Those variables which related to the intellegence level were duration of breastfeeding and the level of mothers education. The mothers education level is one of the factors which has higher effect, againts the childrens intellegence. Those mothers who have high level education will have probability 3,556 to have their children with high level intellegence (after controlling the duration breastfeeding). Suggestion; The Department of Education Bekasi city to organize activities relevant to the improving of parents in growth and development of their children through seminars/training/counseling.

Keywords: Duration of breastfeeding, intellegence, mother education

\section{Pendahuluan}

Untuk mampu mendapatkan pendidikan yang setinggi-tingginya, era globalisasi dan kemajuan ilmu teknologi menuntut generasi yang cerdas. Sebagai tempat pendidikan formal, sekolah dasar berperan positif sebagai proses awal belajar anak yang anak mengenal dan menyesuaikan diri dengan lingkungan. ${ }^{1}$ Dalam proses belajar, kecerdasan merupakan salah satu masalah pokok, banyak orang berpendapat bahwa inteligensi merupakan faktor penting yang ikut menentukan keberhasilan belajar seseorang terutama besar pada anak usia dini. ${ }^{2}$

Setiap individu merupakan produk faktor keturunan yang mewarisi karakteristik genetik dari orang tua dan faktor lingkungan yang didapat dari orang tua, keluarga, teman, sekolah, masyarakat, budaya, dan semua pengalaman anak yang mulai dari saat pembuahan janin

Alamat Korespondensi: Maryam Said, Dinas Kesehatan Kota Bekasi, Jl. Jenderal Sudirman No. 3 Bekasi, Hp. 08129697377, e-mail: maryam_dilah@yahoo.co.id 
dalam kandungan. Kedua faktor tersebut memengaruhi perkembangan intelektual manusia. Ada 15 faktor yang memengaruhi kecerdasan meliputi hereditary factors, twin studies, relationship median correlation, adoption studies, environmental factors, prenatal environment, postnatal environment, home environment, parent-child interaction, social and environmental deprivation, socioeconomic status, race and culture, sex differens, personality dispositions, physiological conditions yang meliputi gizi, kesehatan, obat, penyakit, dan cedera fisik. ${ }^{3}$

Dalam pembangunan bangsa, peningkatan kualitas sumber daya manusia harus dimulai sejak dini, salah satu faktor yang berperanan penting dalam peningkatan kualitas manusia adalah pemberian Air Susu Ibu (ASI) terutama ASI ekslusif yang merupakan langkah awal membangun kesehatan, pertumbuhan fisik dan perkembangan otak secara optimal. ${ }^{4}$ Banyak penelitian yang telah dilakukan tentang manfaat ASI yang diketahui menurunkan mortalitas dan morbiditas, mengoptimalkan pertumbuhan, membantu perkembangan kecerdasan anak, dan membantu menjarangkan kehamilan.

Sejak tahun 1929, banyak studi tentang hubungan antara menyusui dan kecerdasan, dan ditemukan nilai kecerdasan intelektual yang tertinggi dimiliki oleh kalangan anak-anak yang disusui. ${ }^{5}$ Korelasi antara pemberian ASI eksklusif dengan perkembangan kognitif merupakan salah satu dari banyak studi yang dilaporkan. Bayi yang diberi ASI eksklusif terbukti mempunyai keuntungan lebih pada kecerdasan intelektual. Namun, terdapat faktor lain yang terlibat meliputi kecerdasan intelektual ibu, usia ibu, ras ibu, dan status sosial ekonomi. Salah satu bidang studi yang berkembang adalah efek asam lemak Docosahexaenoic Acid (DHA) yang terdapat dalam ASI. DHA tidak didapatkan dalam susu sapi dan susu formula, DHA dalam susu formula adalah berbasis tanaman dan lebih sulit diserap dalam tubuh apabila dibandingkan yang terdapat pada ASI. ${ }^{6}$ Penelitian ini bertujuan mengetahui proporsi tingkat kecerdasan anak, riwayat pemberian ASI, karakteristik ibu dan anak serta faktor dominan yang berhubungan dengan tingkat kecerdasan anak pada siswa SDSN Pekayon Jaya VI Kota Bekasi.

\section{Metode}

Penelitian kuantitatif ini menggunakan desain studi potong lintang. Populasi yang diamati adalah siswa kelas $1-3$ yang berumur 7 - 9 tahun. Besar sampel sebanyak 166 anak beserta ibu siswa dengan pertimbangan pada kelompok anak usia 7 tahun mencetak IQ relatif tinggi. ${ }^{7}$ Teknik pengambilan sampel adalah systematic random sampling. Sampel penelitian adalah yang memenuhi kriteria inklusi dan eksklusi. Tempat penelitian di SDSN Pekayon Jaya VI Kota Bekasi Jawa Barat pada minggu kedua sampai minggu ketiga bulan Mei tahun 2013.
Penelitian ini dilakukan dalam dua tahap meliputi penelitian pendahuluan dan utama. Penelitian pendahuluan dilakukan survei lapangan, uji coba kuesioner dan persiapan untuk pengambilan data. Pada uji coba kuesioner dilakukan pada tanggal 14 Mei 2013, dengan jumlah 30 responden di SDSN Pekayon Jaya V Kota Bekasi. Pada penelitian utama dilakukan pengumpulan data dengan tes kecerdasan menggunakan instrumen tes Raven pada seluruh sampel, dilanjutkan dengan wawancara kepada ibu responden, tatap muka dan wawancara langsung menggunakan kuesioner. ${ }^{8}$

Instrumen penelitian menggunakan tes Raven yang merupakan tes nonverbal untuk mengukur kecerdasan manusia secara umum yang disajikan dalam bentuk visual dan geometris-analogi. ${ }^{9}$ Tes Raven yang paling umum dan populer, dapat diberikan pada usia lima tahun sampai orangtua dan dianggap salah satu pengukuran terbaik karena memberikan ukuran yang optimal dari proses penalaran abstrak yang relevan dengan kerja memori dalam pemecahan masalah. ${ }^{10}$ Tes Raven dikembangkan oleh John C Raven tahun 1936. Format tes ini dirancang dalam bentuk banyak pola, dalam setiap pokok tes, subjek diminta untuk mengidentifikasi unsur yang hilang kemudian melengkapi pola tersebut. Disajikan bentuk pilihan ganda dan bentuk matriks $4 \times 4,3 \times 3$, dan $2 \times 2$ untuk mengukur tes kemampuan penalaran, yang sering disebut sebagai kecerdasan umum (tes kemampuan penalaran). ${ }^{11}$

Pada saat pengambilan data, terdapat beberapa kendala, misalnya ibu yang bekerja maka kuesioner dikirim melalui email sebanyak 7 , ibu yang menolak menjawab kuesioner sebanyak 5 dan alamat rumah tidak ditemukan sebanyak 4 sehingga kuesioner yang terkumpul sebanyak 166 kuesioner $(94,8 \%)$. Analisis multivariat dilakukan untuk memprediksi hubungan antara variabel kecerdasan dan beberapa variabel independen serta untuk mengetahui variabel dominan terhadap kecerdasan maka digunakan model prediksi dan analisis menggunakan uji regresi logistik ganda.

\section{Hasil}

Siswi kelas 1 - 3 SD yang mempunyai kecerdasan rendah sekitar $6 \%$, rata-rata sekitar $36,7 \%$, dan tinggi sekitar 57,2\% (Tabel 1). Ibu yang pernah memberikan ASI kepada anaknya $(93,4 \%)$, apabila $>16$ minggu usia bayi telah diberi minum atau makan, maka dianggap ASI eksklusif hanya sebesar $(39,8 \%)$. Jika $<16$ minggu, maka dianggap tidak ASI eksklusif sebesar $(60,2 \%)$.

\begin{tabular}{lll} 
Tabel 1. Distribusi Menurut Tingkat Kecerdasan & \\
\hline Karakteristik Kecerdasan & $\mathbf{n}$ & $\%$ \\
\hline Rendah & 10 & 6,0 \\
Rata - rata & 61 & 36,7 \\
Tinggi & 95 & 57,2
\end{tabular}


Distribusi riwayat lama responden memberikan ASI kepada bayi selama $<6$ bulan sekitar $30,1 \%$, antara $6-$ 12 bulan sekitar $24,1 \%$, dan selama $\geq 12$ bulan sekitar $45,8 \%$. Berdasarkan karakteristik ibu, terbanyak responden berumur 20 - 35 tahun $(82,5 \%)$. Ibu yang memiliki tingkat pendidikan SMA/sederajat dan akademis/S1/S2/ S3 sekitar 91,6\%. Berdasarkani paritas, melahirkan lebih dari satu kali sekitar $74,1 \%$. Karakteristik anak terbanyak jenis kelamin perempuan sebesar 57,8\%. Riwayat berat badan lahir anak meliputi berat lahir $>2.500$ gram sebanyak 89,2\% dan berat lahir $\leq 2.500$ gram sebanyak $10,8 \%$. Usia kehamilan saat melahirkan meliputi $\geq 37$ minggu sebanyak $68,7 \%$ dan < 37 minggu sebanyak $31,3 \%$. Riwayat anak tidak pernah menderita penyakit kronis sebanyak $65,1 \%$ dan pernah menderita satu atau lebih penyakit kronis sebanyak $34,9 \%$. Sedangkan, riwayat menurut pola asuh usia dini, yang memiliki pola asuh baik sebanyak 54,8\% (Tabel 2).

Terdapat perbedaan yang signifikan antara kecerdasan anak dengan durasi ASI (nilai $p=0,043$ ). Sedangkan, pemberian ASI dan ASI eksklusif tidak memiliki hubungan dengan kecerdasan anak. Terdapat hubungan antara pendidikan ibu dengan kecerdasan anak (nilai $\mathrm{p}=$ 0,047 ), dengan nilai $\mathrm{OR}=3,73$ yang berarti ibu yang berpendidikan tinggi berpeluang 3,73 kali lebih besar untuk mempunyai anak dengan kecerdasan tinggi. Umur ibu dan paritas tidak berhubungan dengan kecerdasan anak, sedangkan karakteristik anak yang meliputi jenis kelamin, usia kehamilan ibu saat anak lahir, berat badan lahir, dan riwayat penyakit kronis, serta pola asuh usia dini tidak berhubungan dengan kecerdasan anak (Tabel $3)$.

Dengan metode regresi logistik ganda model prediksi, didapatkan nilai OR untuk variabel durasi ASI sebesar 0,50. Anak yang mendapat durasi ASI $\geq 12$ bulan berpeluang 0,50 kali lebih kecil untuk mempunyai kecerdasan tinggi $(50,5 \%)$ dibandingkan dengen yang mendapat durasi ASI $<12$ bulan $(67,7 \%)$. Pendidikan ibu yang tinggi berpeluang mempunyai anak kecerdasan tinggi 3,56 kali lebih besar dibandingkan ibu berpendidikan rendah setelah dikontrol variabel durasi ASI (Tabel 4).

\section{Pembahasan}

Anak mempunyai kecerdasan tinggi $(57,2 \%)$, kecerdasan rata-rata $36,7 \%$, dan kecerdasan rendah $6 \%$. Dibandingkan dengan laporan hasil psikotes tahun 2012

Tabel 2. Distribusi Responden Berdasarkan Riwayat Pemberian ASI dan Karakteristik Ibu

\begin{tabular}{|c|c|c|c|}
\hline Variabel Independen & Kategori & $\mathbf{n}$ & $\%$ \\
\hline \multicolumn{4}{|l|}{ Riwayat pemberian ASI } \\
\hline \multirow[t]{2}{*}{ Pemberian ASI } & Tidak mendapatkan & 11 & 6,6 \\
\hline & Mendapatkan & 155 & 93,4 \\
\hline \multirow[t]{2}{*}{ Pemberian ASI eksklusif } & Tidak & 100 & 60,2 \\
\hline & $\mathrm{Ya}$ & 66 & 39,8 \\
\hline \multirow[t]{3}{*}{ Durasi pemberian ASI } & $<6$ bulan & 50 & 30,1 \\
\hline & $6-12$ bulan & 40 & 24,1 \\
\hline & $\geq 12$ bulan & 76 & 45,8 \\
\hline \multicolumn{4}{|l|}{ Karakteristik ibu } \\
\hline \multirow[t]{3}{*}{ Riwayat usia ibu } & $<20$ tahun & 2 & 1,2 \\
\hline & $20-35$ tahun & 137 & 82,5 \\
\hline & $>35$ tahun & 27 & 16,3 \\
\hline \multirow[t]{2}{*}{ Pendidikan ibu } & Rendah & 14 & 8,4 \\
\hline & Tinggi & 152 & 91,6 \\
\hline \multirow[t]{2}{*}{ Paritas } & 1 kali & 43 & 25,9 \\
\hline & $>1$ kali & 123 & 74,1 \\
\hline \multicolumn{4}{|l|}{ Karakteristik anak } \\
\hline \multirow[t]{2}{*}{ Jenis kelamin anak } & Laki - laki & 70 & 42,2 \\
\hline & Perempuan & 96 & 57,8 \\
\hline \multirow[t]{2}{*}{ Riwayat berat lahir anak } & $\leq 2.500$ gram & 18 & 10,8 \\
\hline & $>2.500$ gram & 148 & 89,2 \\
\hline \multirow[t]{2}{*}{ Usia kehamilan saat melahirkan } & $<37$ minggu & 52 & 31,3 \\
\hline & $\geq 37$ minggu & 114 & 68,7 \\
\hline \multirow[t]{2}{*}{ Riwayat penyakit kronis anak } & $\overline{Y a}$ & 58 & 34,9 \\
\hline & Tidak & 108 & 65,1 \\
\hline
\end{tabular}

Tabel 3. Karakteristik Ibu Riwayat Pemberian ASI, ASI Eksklusif, Durasi ASI dan Kecerdasan Murid SD

\begin{tabular}{|c|c|c|c|c|c|c|c|c|}
\hline \multirow{3}{*}{ Variabel } & \multirow{3}{*}{ Kategori } & \multicolumn{4}{|c|}{ Tingkat Kecerdasan } & \multirow{3}{*}{ OR } & \multirow{3}{*}{$95 \%$ CI } & \multirow{3}{*}{ Nilai $p$} \\
\hline & & \multicolumn{2}{|c|}{ Rata-rata } & \multicolumn{2}{|c|}{ Tinggi } & & & \\
\hline & & $\mathbf{n}$ & $\%$ & $\mathbf{n}$ & $\%$ & & & \\
\hline \multirow[t]{2}{*}{ Riwayat pemberian ASI } & Mendapatkan & 67 & 43,2 & 88 & 56,8 & \multirow[t]{2}{*}{0,75} & \multirow{2}{*}{$0,21-2,67$} & \multirow[t]{2}{*}{0,760} \\
\hline & Tidak dapat ASI & 4 & 36,4 & 7 & 63,6 & & & \\
\hline \multirow{2}{*}{ Riwayat ASI eksklusif } & $<16$ minggu & 43 & 43,0 & 57 & 57,0 & \multirow[t]{2}{*}{1,02} & \multirow{2}{*}{$0,55-1,92$} & \multirow[t]{2}{*}{1,000} \\
\hline & $\geq 16$ minggu & 28 & 42,4 & 38 & 57,6 & & & \\
\hline \multirow[t]{2}{*}{ Durasi ASI } & $<12$ bulan & 21 & 32,3 & 44 & 67,7 & \multirow[t]{2}{*}{0,49} & \multirow{2}{*}{$0,25-0,93$} & \multirow[t]{2}{*}{0,043} \\
\hline & $\geq 12$ bulan & 50 & 49,5 & 51 & 50,5 & & & \\
\hline \multirow[t]{2}{*}{ Usia ibu } & $<28$ tahun & 33 & 50,0 & 33 & 50,0 & \multirow[t]{2}{*}{1,63} & \multirow{2}{*}{$0,87-3,06$} & \multirow[t]{2}{*}{0,171} \\
\hline & $>28$ tahun & 38 & 38,0 & 62 & 62,0 & & & \\
\hline \multirow[t]{2}{*}{ Pendidikan ibu } & Rendah & 10 & 71,4 & 4 & 28,6 & \multirow[t]{2}{*}{3,73} & \multirow[t]{2}{*}{$1,12-12,43$} & \multirow[t]{2}{*}{0,047} \\
\hline & Tinggi & 61 & 40,1 & 91 & 59,9 & & & \\
\hline \multirow[t]{2}{*}{ Paritas } & $1 \mathrm{kali}$ & 21 & 48,8 & 22 & 51,2 & \multirow[t]{2}{*}{1,39} & \multirow[t]{2}{*}{$0,69-0,80$} & \multirow[t]{2}{*}{0,450} \\
\hline & > 1 kali & 50 & 40,7 & 73 & 59,3 & & & \\
\hline \multirow[t]{2}{*}{ Pola asuh usia dini } & Kurang & 32 & 42,7 & 43 & 57,3 & \multirow[t]{2}{*}{0,99} & \multirow[t]{2}{*}{$0,54-1,84$} & \multirow[t]{2}{*}{1,000} \\
\hline & Baik & 39 & 42,9 & 52 & 57,1 & & & \\
\hline
\end{tabular}


Tabel 4. Model Regresi Logistik Akhir Determinan Kecerdasan Anak

\begin{tabular}{lllll}
\hline Variabel & B & Nilai p & Exp (B) & CI 95\% \\
\hline ASI/non-ASI & $-0,152$ & 0,837 & 0,859 & $0,201-3,665$ \\
ASI ekslusif & 0,174 & 0,613 & 1,190 & $0,605-2,340$ \\
Durasi ASI & $-0,692$ & 0,040 & 0,501 & $0,259-0,968$ \\
Usia ibu & 0,304 & 0,364 & 1,355 & $0,704-2,609$ \\
Pendidikan ibu & 1,269 & 0,041 & 3,556 & $1,052-12,017$ \\
Paritas & 0,058 & 0,879 & 1,060 & $0,504-2,225$ \\
\hline
\end{tabular}

menggunakan skala culture fair intelligence test (CFIT), didapatkan hasil tes kecerdasan intelektual untuk kelas 1 - 3, meliputi yang mempunyai tingkat kecerdasan tinggi $(76 \%)$, rata-rata $(18,5 \%)$, dan rendah $(5,7 \%) .{ }^{12}$ Tampak ada perbedaan hasil tes, kemungkinan karena perbedaan alat tes. Penelitian lain menggunakan tes the Wechsler intelligence test for children (WISC-R) pada kelompok anak sekolah yang berusia 7 tahun mempunyai kecerdasan intelektual sangat tinggi atau tinggi $(30,5 \%)$, kecerdasan intelektual di atas rata-rata $(50,0 \%)$, dan tingkat kecerdasan intelektual rata-rata $(19,5 \%)$. Tes WISC-R dikembangkan oleh Dr. David Wechsler tahun 1939, merupakan tes kecerdasan untuk anak-anak usia 6-16 tahun, tes ini untuk mengukur skala verbal dan kinerja, dirancang untuk mengukur kinerja intelektual seseorang.

Tidak ada perbedaan kecuali durasi pemberian ASI < 12 bulan $(67,7 \%)$ mempunyai kecerdasan tinggi, tetapi durasi ASI $\geq 12$ bulan hanya ada $(50,5 \%)$. Peranan durasi pemberian ASI $<12$ bulan dapat menciptakan kecerdasan anak yang tinggi. Hasil ini kemungkinan dipengaruhi oleh faktor ibu seperti recall bias, status bekerja, usia, pendidikan, paritas, dan faktor anak seperti gizi, riwayat penyakit dan lingkungan/pola asuh. Bagaimanapun, ASI tetap dibutuhkan anak hingga usia dua tahun untuk imunitas tubuh dan tumbuh kembang secara optimal. Intervensi dengan meningkatkan frekuensi menyusui tidak hanya meningkatkan kesehatan anakanak, tetapi juga keterampilan kognitif dan non-kognitif mereka. ${ }^{16}$

Menyusui berhubungan dengan total skor kecerdasan intelektual anak-anak dan durasi ASI berkorelasi dengan total skor kecerdasan intelektual 5,49 poin lebih tinggi tetapi menjadi tidak signifikan setelah penyesuaian dengan faktor confounding. ${ }^{14}$ Perkembangan intelektual anak dipengaruhi oleh warisan genetik dan pengalaman lingkungan, menyusui merupakan awal pengalaman postnatal tersebut. Anak mendapat ASI mencapai skor kecerdasan intelektual lebih tinggi daripada anak-anak tidak diberi ASI, mungkin karena asam lemak unik yang terdapat dalam ASI. ${ }^{15}$

Hanya pendidikan ibu yang berhubungan dengan kecerdasan anak, didapatkan sebanyak 59,9\% mempunyai anak kecerdasan tinggi dengan nilai $\mathrm{p}=0,047$, dan nilai $\mathrm{OR}=3,73$ yang berarti ibu yang berpendidikan tinggi mempunyai peluang 3,73 kali lebih besar untuk mempunyai anak dengan kecerdasan tinggi. Interaksi antara pendidikan ibu yang tinggi dan menyusui menunjukkan hubungan positif terhadap kecerdasan intelektual verbal $(\mathrm{F}=2,64$; nilai $\mathrm{p}=0,005)$ pada anak yang mendapat ASI lebih lama, sedangkan pengenalan dini susu selain ASI dikaitkan dengan kecerdasan intelektual verbal yang berkurang setelah dikontrol confounding untuk sosial dan perinatal. ${ }^{16}$ Terdapat hubungan positif antara durasi pemberian ASI dan perkembangan kognitif setelah dikontrol oleh faktor usia ibu, pendidikan ibu, kecerdasan ibu, dan merokok saat hamil, tetapi tidak ada hubungan antara durasi pemberian ASI pada perkembangan motorik anak usia 13 bulan atau 5 tahun. ${ }^{17}$

Pada penelitian ini, usia ibu terbanyak adalah 20 - 35 tahun yang merupakan usia terbaik karena organ-organ reproduksi wanita telah matang dan siap berproduksi. Usia tersebutakan meminimalkan risiko saat kehamilan dan melahirkan anaknya. Ibu dengan riwayat paritas lebih dari satu kali, telah berpengalaman mengasuh dan mendidik anak. Ibu yang berpendidikan tinggi mempunyai pengetahuan yang lebih baik tentang pertumbuhan dan perkembangan anak sehingga tetap memberikan ASI kepada anak $(93,4 \%)$. Pada umumnya, ibu dapat memenuhi kebutuhan makanan bergizi anak karena hanya $1,2 \%$ riwayat anak mengalami anemia gizi. Pengaruh pola asuh anak usia dini juga penting karena $54,8 \%$ anak riwayat pola asuh baik dalam lingkungan keluarga yang berperan dalam tumbuh kembang anak secara fisik dan kognitif. Pendidikan ibu merupakan variabel dominan yang berpengaruh terhadap kecerdasan anak di SDSN Pekayon Jaya VI Kota Bekasi.

Semua variabel karakteristik anak tidak berhubungan dengan riwayat usia kehamilan ibu saat melahirkan, yaitu lebih dari 37 minggu. Pada waktu ini, pertumbuhan organ-organ penting dalam tubuh sudah siap berfungsi sehingga saat kelahiran berisiko akan minimal dan tidak menghambat pertumbuhan fisik anak. Riwayat berat badan lahir bergantung pada usia kehamilan, yaitu lebih dari 37 minggu maka berat badan lahir akan lebih dari 2.500 gram. Namun, pada kondisi tertentu ibu, misalnya kurang gizi saat hamil, maka berat badan lahir anak tidak sesuai dengan usia kehamilan. Sedangkan, anak yang mempunyai riwayat penyakit kronis sejak lahir hingga sekarang seperti pneumonia/nonpneumonia, kejang demam, dan anemia gizi kemungkinan memengaruhi perkembangan kecerdasan anak ketika masa pertumbuhan otak sehingga anak yang kecerdasannya tinggi mempunyai riwayat penyakit kronis $(55,2 \%)$ lebih rendah daripada anak yang tidak mempunyai riwayat penyakit kronis $(58,3 \%)$.

\section{Kesimpulan}

Anak yang mendapat ASI sebesar 56,8\%, durasi ASI 
kurang dari 12 bulan sebesar $67,7 \%$ menyumbangkan anak dengan kecerdasan tinggi, sedangkan ASI eksklusif atau tidak eksklusif hampir sama masing-masing menyumbangkan $57,0 \%$ dan $57,6 \%$. Namun, durasi ASI $\geq$ 12 bulan hanya menyumbangkan sekitar $50,5 \%$ anak yang kecerdasan tinggi bila dibandingkan dengan karakteristik ibu, yaitu usia lebih dari 28 tahun sekitar 62,0\%, pendidikan ibu tinggi sekitar 59,9\%, paritas lebih dari 1 kali sekitar 59,3\%. Pola asuh besarnya hampir sama menyumbangkan $57,3 \%$ dan $57,1 \%$. Beberapa variabel tidak signifikan kecuali durasi ASI dan pendidikan ibu yang tinggi setelah dikontrol variabel independen lain.

\section{Saran}

Peran orang tua terhadap tumbuh kembang anak penting sehingga setiap ibu menyadari untuk tetap memberikan ASI kepada anak walaupun ibu bekerja serta menciptakan lingkungan yang edukatif sehingga kognitif dapat berkembang optimal. Perlu dilakukan penelitian lanjutan dengan sampel yang lebih besar dengan menggunakan variabel yang lebih luas seperti kecerdasan ibu, riwayat pemberian ASI, riwayat merokok saat hamil, sosioekonomi keluarga, lingkungan yang edukatif, dan pola asuh.

\section{Ucapan Terima Kasih}

Peneliti mengucapkan terima kasih kepada Kepala PPSDM Kementerian Kesehatan Republik Indonesia yang telah memberikan beasiswa tugas belajar program pascasarjana Universitas Indonesia.

\section{Daftar Pustaka}

1. Bararah VF. Hanya 15 persen bayi Indonesia yang diberi ASI eksklusif. Detik health. 29 Maret 2011 [diakses tanggal 23 Juni 2012]. Diunduh dalam: http://health.detik.com/read/2011/03/29/125146/160 3616/764/hanya-15-persen-bayi-indonesia-yang-diberi-asi-eksklusif.

2. Sumadi Suryabrata. Psikologi pendidikan. Edisi ke-5. Jakarta: Rajawali Pers; 2012.

3. Krishna. 16 factors that influences peoples intelligence [online]. 2011 [cited 2012 Oct 5]. Available from: http://www.preservearticles .com/201104195550/16-factors-that-influences-peoplesintelligence.html.

4. Sihadi, Sri PH. Pencapaian pemberian ASI sampai dua tahun di Indonesia. Buletin Penelitian Sistem Kesehatan. 2008; 11 (4); 383-6.

5. Geoff D, G David B, Ian JD. The effect of breastfeeding on intelligence in children: prospective study, sibling pairs analysis and meta-analysis. BMJ [serial on internet]. 2006 [ cited 2013 January 30]; 333. Available from: http://www.bmj.com/highwire/filestream/391494/field_highwire_article_pdf_abri/0.

6. Jeanette MC. One response to baby brains and breastfeeding : the effects of exclusive breastfeeding on cognitive development [cited 2011 November 7]. Available from: http://breastfeedchicago.wordpress.com/2011/11/07/baby-brains-and-breastfeeding-the-effects-of-exclusive-breastfeeding-on-cognitive-development/.

7. Jedrychowski W, Perera F, Jankowski J, Butscher M, Mroz E, Flak E,et al. Effect of exclusive breastfeeding on the development of children's cognitive function in the Krakow prospective birth cohort study. Euro J Pediatry [serial on internet]. 2012 [cited 2012 May 22]; 171 (1); 1518. Available from: http://link.springer.com/journal/431/171/1/page/1.

8. Strauss JF, Witoelar B, Sikoki,Wattie AM. The fourth wave of the Indonesian family life survey (IFLS4): overview and field report”. WR675/1-NIA/NICHD; April 2009 [cited 2013 March 2009] . Available from: http://www.rand.org/labor/FLS/IFLS/ifls4.html.

9. Kunda M, McGreggor K, Goel A. Addressing the Raven's progressive matrices test of "general" intelligence. Papers from the AAAI Fall Symposium (FS-09-05) [online]. 2009 [cited 2013 Jun 3]. Available from: www.aai.org/ocs/index.php/fss/fss09/paper/download/954/1200.

10. Mika H, Motoichiro K, Kazue I, Haruo K. Superior fluid intelligence in children with Asperger's disorder. Brain Cogn [serial on internet]. 2008 Apr [cited 2013 Jun 3] ;66(3):306-10. Epub 2007 Nov 5. Available from: http://www.ncbi.nlm.nih.gov/pubmed/17980944.

11. Thorsdottir I, Gunnarsdottir I, Kvaran MA, GretarssonSJ. Maternal body mass index, duration of exclusive breastfeeding and children's developmental status at the age of 6 years. Eur J Clin Nutr [serial on internet]. 2005 Mar [cited 2013 Jul 5]; 59(3): 426-31, Available from: http://www.ncbi.nlm.nih.gov/pubmed/15674314.

12. Dinas Pendidikan Pemerintah Propinsi Jawa Barat. Profil Sekolah Dasar Negeri Pekayon Jaya VI, potensial menuju SSN. Kota Bekasi Jawa Barat: Dinas Pendidikan Pemerintah Propinsi Jwa Barat; 2013.

13. Borra C, Maria I, Sevilla A. The effect of breastfeeding on children's cognitive and noncognitive development [manuscript on internet]. IZA Discussion Paper serie No. 6697 June 2012 [cited 2013 January 26]. Available from: http://ftp.iza.org/dp6697.pdf.

14. Holme A, MacArthur C, Lancashire R. The effects of breastfeeding on cognitive and neurological development of children at 9 years. Child Care health Develop [serial on internet]. 2010 [cited 2013 January 12]; 36 (4): 583-90. Available from: http://onlinelibrary.wiley.com/doi/10.1111/cch.2010.36.issue-4/issuetoc.

15. Caspi A, Williams B, Cohen KJ, Craig IW, Milne BJ, Poulton R, et al. Moderation of breastfeeding effects on the IQ by genetic variation in fatty acid metabolism. PNAS [serial on internet]. 2007; 104 (47) [2012 May 18]. Available from: http://www.pnas.org/content/104/47/18860.long.

16. Oddy WH, Kendall GE, Blair E, De Clerk NH, Stanley FJ, Louis I. Breast feeding and cognitive development in childhood: a prospective birth cohort study. Paediatric and Perinatal Epidemiology. 2003; 17(1): 81-90.

17. Angelsen NK, Vik T, Jacobsen G, Bakketeig LS. Breast feeding and cognitive development at age 1 and 5 years. Arch Dis Child [serial on internet]. 2001 [2011 May 24]; 85: 183-8. Available from: http://adc.bmj.com/content/85/3/183. 